\title{
TENDÊNCIAS SOBRE PUBLICIDADE E CONSUMO EM REVISTAS CIENTÍFICAS DA COMUNICAÇÃO QUALIS A2 ENTRE 2006 E 2017. PUBLICIDADE E CONSUMOS DIGITAIS EM FOCO'
}

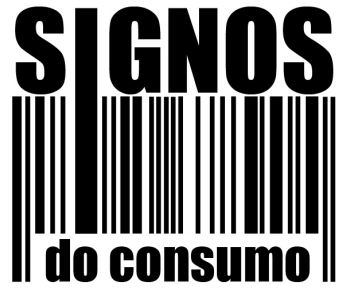

artigo

\author{
Trends on advertising and consumption in scientific \\ communication journals of Qualis A2 from 2006 to 2017. \\ Advertising and digital consumption in focus
}

Tendencias sobre la publicidad y el consumo en revistas científicas de comunicación Qualis A2 entre 2006 y 2017. Publicidad y consumo digital en foco

\author{
Eneus Trindade \\ Universidade de São Paulo, São Paulo, Brasil. \\ Professor associado da Universidade de São Paulo (USP), livre-docente em Comunicação Publicitária, \\ atuando no Programa de Pós-Graduação em Ciências da Comunicação (PPGCOM) e na graduação \\ em Publicidade e Propaganda. Vice-coordenador do Grupo de Estudos Semióticos em Comunicação, \\ Cultura e Consumo (GESC ${ }^{3}$ ) do Conselho Nacional de Desenvolvimento Científico e Tecnológico \\ (CNPq) e da USP e bolsista de produtividade em pesquisa nível 2 do CNPq. \\ E-mail: eneustrindade@usp.br
}

RESUMO Este trabalho apresenta os resultados qualitativos da coleta de dados das revistas classificadas no estrato Qualis Capes A2 em Comunicação - o mais qualificado no contexto brasileiro -, para discutir o espaço do subcampo publicidade e consumo no foco do digital no que diz respeito aos autores, às instituições, aos seus assuntos e às perspectivas teórico-metodológicas dos artigos publicados entre 2006 e 2017. A metodologia da coleta de dados é inspirada no trabalho de Kim, Hayes, Avant e Reid. Os resultados mostram uma presença pequena da publicidade propriamente dita, mas um grande avanço das questões de circulação, usos e consumos midiáticos de mídias, marcas, produtos culturais e serviços digitais. As pesquisas são majoritariamente exploratórias e qualitativas, no espectro do que se pode denominar como estudos de mídia.

PALAVRAS-CHAVE Publicidade, Consumos, Mídias Digitais, Teorias, Metodologias.
ABSTRACT This work presents the qualitative results of data collection of the journals classified in the Qualis Capes A2 stratum in Communication - the most qualified in the Brazilian context -, to discuss the space of the publicity and consumption subfield focusing on digital with regard to the authors, institutions, their subjects and the theoretical-methodological perspectives of articles published from 2006 to 2017. The methodology of data collection is inspired by the work of Kim, Hayes, Avant and Reid. The results show a small presence of advertising itself, but a major advance in the issues of circulation, use and media consumption of media, brands, cultural products and

1. Trabalho apresentado no grupo de pesquisa Publicidade e Propaganda, XVIII Encontro dos Grupos de Pesquisas em Comunicação, evento componente do $41^{\circ}$ Congresso Brasileiro de Ciências da Comunicação. 
digital services. The researches are mostly exploratory and qualitative, in the spectrum of what can be termed as media studies.

KEYWORDS Advertising, Consumption, Digital Media, Theories, Methodologies.

RESUMEN El presente trabajo presenta los resultados cualitativos de la recolección de datos de las revistas clasificadas en el nivel Qualis Capes A2 en Comunicación -el más calificado en el contexto brasileño- para discutir el espacio del subcampo publicidad y consumo centrándose en lo digital en lo que se refiere a los autores, a las instituciones, a los temas y a los marcos teóricos y metodológicos de los artículos publicados entre 2006 y 2017. La metodología de recolección de datos se basa en el trabajo de Kim, Hayes, Avant y Reid. Los resultados demuestran poca presencia de la publicidad propiamente dicha, pero un gran avance de las cuestiones de difusión, usos y consumos mediáticos de los medios, de las marcas, de los productos culturales y de los servicios digitales. La mayoría de las investigaciones son exploratorias y cualitativas, en el campo de lo que se puede considerar como estudios de los medios.

PALABRAS CLAVE Publicidad, Consumos, Medios Digitales, Teorías, Metodologías.

\section{INTRODUÇÃO}

Este trabalho apresenta os resultados qualitativos coletados das revistas classificadas no estrato Qualis Capes A2 em Comunicação o mais qualificado no contexto brasileiro para as revistas científicas nacionais do campo -, para discutir o espaço do subcampo publicidade e consumos no foco do digital, quanto aos autores, às instituições, aos seus assuntos e às perspectivas teórico-metodológicas dos artigos publicados entre 2006 e 2017. A metodologia da coleta de dados é inspirada nos trabalhos de Kim et al. (2014) e Yale e Gilly (1988). Os resultados mostram uma presença pequena da publicidade propriamente dita, mas um grande avanço das questões de circulação, usos e consumos midiáticos de mídias, marcas, produtos culturais e serviços digitais. As pesquisas são majoritariamente exploratórias e qualitativas, no espectro daquilo que podemos denominar como estudos de mídia.

O artigo é um recorte da pesquisa do autor sobre as "Tendências da pesquisa em publicidade e consumo no Brasil - 2006 a 2018: a construção de um subcampo da pesquisa em comunicação”, financiada pelo Conselho Nacional de Desenvolvimento Científico e Tecnológico (CNPq) com Bolsa Produtividade em Pesquisa nível 2, cujo foco são os textos publicados sobre publicidade e consumo.

A relevância deste tipo de pesquisa se dá pela problematização da possibilidade de verificar o estágio de maturidade da divulgação científica das pesquisas sobre o tema no Brasil, em função de uma série de conquistas institucionais e científicas desse subcampo, descritas a seguir.

Hoje, entre os mais de 50 programas de pós-graduação (PPG) em Comunicação credenciados na Coordenação de Aperfeiçoamento de Pessoal de Nível Superior (Capes) pelos registros de presença nos congressos da Sociedade Brasileira de Estudos Interdisciplinares do Comunicação (Intercom); no Núcleo de Pesquisa em Publicidade e Propaganda; nos eventos do Encontro Nacional de Pesquisadores em Publicidade e Propaganda (Pró-Pesq PP) da Associação Brasileira de Pesquisadores em Publicidade (ABP2); e no Congresso Internacional em Comunicação e Consumo (Comunicon) da Escola Superior de Propaganda e Marketing (ESPM), os que abordam questões de comunicação e consumo totalizam, numa conta aproximada, 25. Isto significa que 
praticamente $50 \%$ do total dos programas da área, com pesquisadores e discentes, estudam temas do eixo publicidade e consumos. Essa participação se aproxima, inclusive, da discussão da produção discente sobre o eixo apresentada no trabalho de Peres-Neto (2016, p. 9). E somase a esse crescimento da temática o registro, desde 2015, da criação do grupo de trabalho (GT) Consumos e Processos de Comunicação na Associação Nacional dos Programas de Pós-Graduação em Comunicação (Compós), que está na sua quarta edição em 2018 e que se manteve na última reclivagem realizada pela associação no mesmo ano.

Além disso, acrescentamos que o termo consumo passa a configurar em nomes de PPG, linhas de pesquisa da área de Comunicação e periódicos: PPG em Comunicação e Práticas de Consumo da ESPM-SP; a Linha de Pesquisa intitulada "Consumo e usos midiáticos nas práticas sociais” do PPG em Ciência da Comunicação da Universidade de São Paulo (PPGCOM/USP); e os periódicos da área de comunicação que tratam do tema, a saber: Comunicação, Mídia e Consumo, da ESPM (Qualis A2) e Signos do Consumo do PPGCOM/USP (Qualis B2).

Por fim, agregamos aos argumentos que endossam essa percepção de crescimento da área de comunicação e consumo o diagnóstico preliminar apresentado por Peres-Neto (2016), no GT de Consumos e Processos de Comunicação da Compós que, ao iniciar estudos a respeito da produção de teses e dissertações sobre o tema no Brasil, identifica alguns resultados importantes que fortalecem a relevância de sentido desta proposta: o trabalho mencionado identifica no banco de teses e dissertações da Capes 70 títulos distribuídos em 24 programas da área de Comunicação, cuja maior quantidade está nas regiões Sudeste e Sul, nos seguintes programas: ESPM, Pontifícia Universidade Católica de São Paulo (PUC-SP), USP, PUC do Rio Grande do Sol (PUCRS), Universidade Metodista de São Paulo (Umesp), Universidade do Estado do Rio de Janeiro (Uerj), PUC do Rio de Janeiro (PUC-Rio), Universidade do Vale do Rio dos Sinos (Unisinos), Universidade Federal do Rio de Janeiro (UFRJ), permitindo a identificação de centros formadores no tema entre São Paulo, Rio de Janeiro e Rio Grande do Sul. Ademais, ressaltamos que dentro do universo da comunicação e consumos, as interfaces entre publicidade e consumo constituem $24 \%$ do total de teses e dissertações registradas. A maioria dessas produções encontra-se entre os períodos de 2011 e 2012 (PERES-NETO, 2016, p. 7-11). Essas informações mostram que existe o crescimento de um eixo de pesquisa na área, fruto do trabalho de pesquisadores de publicidade, que ganha relevância e merece a nossa atenção.

Nesse sentido, as hipóteses que sustentam a proposta de estudo do estado de conhecimento sobre tal produção configuram-se nas seguintes formulações:

Hipótese 1: as publicações brasileiras em periódicos qualificados sobre publicidade e consumos apontam para um caminho de construção sólida de um subcampo de estudos na Comunicação; Hipótese 2: as publicações brasileiras em periódicos qualificados sobre publicidade e consumos se configuram como um subcampo desconexo sem direcionamentos teóricometodológicos robustos, com objetos de análises que se direcionam a uma contribuição gerencial para a área da Comunicação e não como contribuições científicas de fato (TRINDADE, 2017, p. 34).

As duas hipóteses formuladas nos demandam os seguintes questionamentos: tais artigos apresentam discussões teóricas para o enquadramento de seus objetos? Quais são as teorias e disciplinas mais 
recorrentes nestes textos? Qual o enfoque nas mídias desses artigos, considerando o trabalho em publicidade e consumo como parte dos fenômenos dos estudos de mídia? Os textos priorizam a pesquisa empírica ou teórica? As abordagens dessas pesquisas são quantitativas, qualitativas ou mistas? Quais os métodos aplicados? Esses artigos se referem ou não aos estudos de efeitos (se sim, de quais tipos)? Quais as unidades de análise (tipos de sujeitos investigados, documentos midiáticos)? E, finalmente, qual o propósito geral dos textos, no que diz respeito à perspectiva de continuidade das pesquisas apresentadas nos artigos?

Os objetivos desta pesquisa são responder às questões apresentadas. Cabe esclarecer ainda que a delimitação deste artigo ocorreu pelo fato de que o primeiro levantamento das revistas Qualis A2 mostrou-se volumoso, com 2.274 artigos, pois a pesquisa maior também inclui aquelas com qualificação Qualis B1, correndo também em paralelo com um estudo comparado com as revistas mais qualificadas francesas da área de comunicação, a partir de um pós-doutorado realizado pelo autor deste artigo na França no âmbito do Laboratoire de Recherche en Sciences de L'Information et de la Communication (Gripic), financiado pelo Centro de Estudos Literários e Científicos Aplicados (Celsa) da Universidade de Sorbonne, Paris, sob o foco da publicidade e consumos digitais, mas que aqui será apresentado apenas nos resultados referentes ao Brasil e das revistas Qualis A2.

Nesse sentido, cabem alguns esclarecimentos sobre a concepção que temos do objeto publicidade e consumos para depois apresentarmos o corpus das revistas estudadas, a metodologia da coleta de dados e os resultados.

A publicidade e os consumos são aqui compreendidos como um subcampo das relações do campo da Comunicação com os vários tipos e processo de consumos. E ao considerarmos o cenário contemporâneo, somos confrontados com uma expansão ou um transbordamento das ações institucionais e promocionais que vão além dos formatos tradicionais de publicidade, demarcando uma série de novas conceituações, como foi apresentado resumidamente por Trindade (2017, p. 34):

esse transbordamento tem gerado um série de reflexões na área no contexto da comunicação brasileira e no mundo que fazem surgir ideias, termos, conceitos que buscam dar conta dessa expansão dos signos do sistema publicitário cuja nomenclatura não cabe nas designações de publicidade e propaganda, a saber: Ecossistema publicitário (Perez, 2017), Hiperpublicidade (Perez e Barbosa, 2007), Publicidade Híbrida (Covaleski, 2010), Publicização (Casaqui, 2011), Promocionalidade (Castro, 2016), hiperpublicitarização, despublicitarização (BerthelotGuiet; Montety; Patrin-Lecleré, 2016). Há também as nomenclaturas do mercado publicitário que tratam da publicidade crossmedial transmídia, brand content entre outras possiblidades de modismos ou novos nomes. Todas essas novas denominações surgem, portanto, do fato de que quando se fala em publicidade e propaganda, hoje se vai além de anúncios/comerciais. Trata-se de compreender, na atualidade uma dinâmica interacional entre marcas e consumidores que foge a semântica de termos publicidade e propaganda, que nos tem obrigado ao estudo de novas denominações para as estratégias de marcas, sobretudo frente à crescente presença das plataformas digitais na mediação dessas interações. 
É nessa esteira de reflexões que o termo consumo vem aplicado na função plural, pois ele também tem amplas acepções e é utilizado para expandir o escopo dos objetos da mediação cultural dos mercados na vida cotidiana, bem como para ir além das concepções dos estudos de recepção tradicionais e trabalhar os consumos midiáticos culturais e digitais como discutem Toaldo e Jacks (2017) e Montardo (2016), numa dinâmica de seus usos e apropriações nos contextos específicos de estudos.

Após esses importantes esclarecimentos, apresentamos a metodologia do trabalho e o corpus da pesquisa.

\section{A METODOLOGIA E O CORPUS}

A metodologia para a pesquisa está apoiada nos trabalhos de Kim et al. (2014) e Yale e Gilly (1988), sobre tendências da pesquisa na publicidade, cujos objetivos eram oferecer informações sobre aspectos bibliométricos das pesquisas em publicidade no contexto norte-americano da comunicação e marketing entre os anos de 1980 a 2010. Embora a pesquisa tenha um caráter qualitativo, seus elementos de registro permitem uma primeira apreciação qualitativa da produção registrada e, nesse sentido, o método aqui aplicado sofreu adaptações em relação à proposta anterior.

Os aspectos considerados para o registro foram: nome completo dos autores; título dos artigos; ano do periódico; perfil/escopo do periódico; nome da revista; resumo; palavras-chave; se a teoria está presente ou não; nome das teorias utilizadas; disciplinas; autores seminais; variáveis dependentes ou independentes (aspectos estes que não se mostraram rentáveis, pois os trabalhos eram em sua maioria qualitativos); assuntos dos artigos (prática publicitária; efeitos da publicidade; efeitos declarados da publicidade social, econômica, sobre conteúdo de marketing); temas sociais (gênero, etnia, idade, religião); inclusão social de pessoas portadoras de necessidades especiais; inclusão digital; outras inclusões; diferenças culturais de modos de vida; vida do trabalho; consumo cultural, digital e midiático; conteúdos publicitários; métodos de pesquisa, sustentabilidade ambiental e outros; artigos empíricos ou não; qualitativos, quantitativos ou mistos; Métodos de pesquisas: laboratorial, experiência de campo, análise longitudinal, surveys, grupo de discussão, entrevistas, análise de conteúdo, análise textual/ discursiva, análises estatísticas, estudos de caso, meta-análise, etnografia, análise histórica, revisão sistemática, multimétodos, outros; mídias de interesse: televisão, rádio, impressos, bellow the line; ambientes digitais; ambientes digitais móveis; filmes, sem mídias, todas as mídias, outras; tipos de efeitos: cognitivos, afetivos; comportamentais, psicológicos, produção social de sentido, econômico, outros; unidades de análise: anúncios, crianças, adultos, mulheres, homens, estudantes, profissionais do setor de mídia, dados secundários, vídeos, adolescentes (de 12 a 17 anos), mistura de produtos publicitários, combinações, outros; implicações do artigo: teórica, prática publicitária e de marketing, metodológica, políticas públicas, educação, outros; indicação de estudos futuros ou não.

Cabe destacar que o escopo de artigos identificados sobre publicidade e consumos com foco no digital incluiu o universo semântico das seguintes palavras-chave: publicidade, marcas, midiático, comunicação estratégica, digital, estratégias digitais, redes sociais digitais, consumo, consumo midiático, consumo cultural, consumo digital, cibercultura, usos midiáticos, mercantilização, user generated content, branded content, consumidor, campanhas online e dispositivos móveis. 
A partir desses elementos, lançou-se olhar sobre o corpus composto das seis revistas Qualis Capes A2 do país:

MATRIZes (USP) - foi criada em 2007 e é uma jovem revista científica sobre Comunicação com edição bilingue (português e inglês) do tradicional PPGCOM da USP (um programa pioneiro no país, com 46 anos de existência). Em 2017 o periódico passou de semestral para quadrimestral.

Galáxia (PUC-SP) - revista tradicional na área de Comunicação que pertence ao Programa de Pós-graduação em Comunicação e Semiótica da PUC-SP (também um programa pioneiro, com 47 anos de existência). A revista já possui 36 anos de atividades. Em 2017 o periódico passou de semestral para quadrimestral.

Revista Brasileira de Ciências da Comunicação (RBCC) (Intercom) - a $R B C C$ tem 41 anos de atividades. É o periódico mais antigo da área de Comunicação e pertence à maior entidade científica da área - a Intercom. Em 2015 a revista passou de semestral para quadrimestral.

Comunicação, Mídia e Consumo (CMC) (ESPM) - a CMC foi criada em 2004 pelo Programa de Pós-Graduação de Comunicação e Práticas de Consumo da ESPM de São Paulo. É a revista especializada nos assuntos de comunicação e consumo com forte aderência aos temas da publicidade e consumo. O periódico sempre foi quadrimestral.

E-Compós (Compós) - a revista foi criada em 2004 e é, entre os seis periódicos estudados, o segundo a pertencer a uma entidade científica importante da área, como no caso da Intercom. Trata-se da Compós. Em 2016 a revista passou a ser quadrimestral.

Famecos (PUCRS) - periódico do Programa de Pós-Graduação em Ciências da Comunicação da PUC-RS. Tem 22 anos. Trata-se do programa mais antigo fora do eixo Rio-São Paulo e o seu periódico sempre foi quadrimestral.

Observa-se que quatro dos periódicos se concentram no estado de São Paulo (MATRIZes, RBCC, CMC e Galáxia). Apensas duas revistas têm sede fora de São Paulo, uma no Rio Grande do Sul (Famecos) e outra em Brasília (E-Compós). Duas pertencem às entidades científicas mais importantes da área no país Intercom e Compós e duas são de programas pioneiros do país (USP e PUC-SP, com mais de 40 anos de atividades). A revista Famecos da PUCRS é a mais antiga da região Sul.

A $C M C$ é a única cujo escopo é totalmente orientado ao interesse da pesquisa e é a que possui maior quantidade de artigos no tema publicidade e consumos, por razões óbvias, como iremos ver nos resultados a seguir.

Nota-se também que a partir de 2015 as revistas que eram semestrais passam a ser quadrimestrais, visando a indexação em bases de dados internacionais como Web of Sciense e Scopus, o que permite a elas pleitear a classificação no estrato Qualis Capes A1 de periódicos.

\section{RESULTADOS PRINCIPAIS E PARCIAIS}

A realização de estudos dessa natureza não oferece avanços à área em termos de novas descobertas, mas permite identificar o tipo de presença ou ausência que dada temática científica ocupa em certo campo com suas disputas nos espaços acadêmicos, como diria Pierre Bourdieu (1983). Isto é, podem ser feitas considerações sobre o modo como essa ocupação vem sendo realizada, neste caso, no campo dos estudos sobre a publicidade e os consumos digitais, no âmbito das pesquisas em Comunicação. 
Isso se fundamenta a partir da possibilidade de identificação de autores, teorias, métodos e assuntos das pesquisas publicadas, o que permite a construção de aspectos do campo a partir da produção científica e algumas inferências sobre a possibilidade de compreensão do habitus dos pesquisadores da temática aqui em foco, diante das suas práticas de pesquisa no campo. Dito isso, identificam-se os seguintes resultados principais, a seguir.

Tabela 1. Número geral de artigos sobre publicidade e consumos e publicidade e consumos digitais por revistas.

\begin{tabular}{|c|c|c|c|}
\hline Revista & $\begin{array}{c}\text { № de artigos } \\
\text { de 2006-2017 e } \\
\text { edições }\end{array}$ & $\begin{array}{c}\text { Publicidade e } \\
\text { consumos }\end{array}$ & $\begin{array}{l}\text { Publicidade e } \\
\text { consumos digitais }\end{array}$ \\
\hline E-Compós & 471 - 36 ed. & 28 & 9 \\
\hline RBCC & $279-26$ ed. & 30 & 10 \\
\hline CMC & 319 - 36 ed. & 155 & 55 \\
\hline Famecos & 582 - 38 ed. & 47 & 15 \\
\hline MATRIZes & 260 - 23 ed. & 10 & 4 \\
\hline Galáxia & $363-26$ ed. & 26 & 8 \\
\hline Total & $2.274-185$ ed. & 296 & 101 \\
\hline$\%$ & $100 \%$ & $13,01 \%$ & $4,4 \%$ \\
\hline
\end{tabular}

A Tabela 1 mostra um panorama da ocupação dos artigos no conjunto dos anos estudados. Os anos com maior publicação são 2017 (17 artigos), 2008 (11 artigos) e 2012, 2013 e 2015 (10 artigos por ano). 2016 teve 9 artigos e os outros anos publicaram no máximo 8 artigos.

Cabe esclarecer que existem mais artigos sobre comunicação digital, mas que, em função dos contornos léxico-semânticos das palavras-chave da temática selecionada para esta pesquisa, não foram incorporados ao corpus.

Salienta-se que o corpus a ser descrito precisa ser melhor analisado, a partir da coleta de dados. Aqui, compartilha-se uma caracterização geral das primeiras impressões do que foi encontrado nos artigos.

O tema da publicidade e os consumos ocupam 13\% do total de 2.274 artigos identificados, sendo maior o número de textos referentes aos estudos de consumos na Comunicação do que sobre os estudos de comunicação estratégica/publicidade propriamente ditos. Isso se repete também na identificação dos estudos de publicidade e consumos digitais, pois tais trabalhos correspondem a 4,4\% (101 artigos) do total de 2.274) registrados, dos quais 20 artigos ou $0,87 \%$ do total correspondem a $20 \%$ dos textos sobre publicidade e consumos digitais, tratando especificamente sobre os estudos de comunicação estratégica/publicidade digital.

Dos artigos sobre publicidade e consumos digitais, 55\% estão publicados na revista Comunicação, Mídia e Consumo da ESPM, cujo escopo refere-se ao tema desta pesquisa. A temática aparece nas demais revistas com a seguinte frequência: Famecos 15\%, RBCC 10\%, E-Compós 9\%, Galáxia 8\% e MATRIZes 4\%. Famecos e CMC revelam-se como espaços privilegiados para aceitar publicações de artigos do tema 
publicidade e consumos digitais. Nas demais publicações o tema fica pulverizado, não ultrapassando $10 \%$ do total de artigos da revista.

Considerando-se a multiplicidade e os enfoques que o campo da Comunicação oferece, pode-se depreender que há certa presença do tema publicidade e consumos digitais, mas que é menor do que outros assuntos do campo comunicacional, como cinema e jornalismo.

Além disso, os dados sinalizam que os temas da publicidade e consumos digitais, sobretudo o da publicidade, não estão sendo muito abordados nas revistas estudadas. E lembramos que essas são as principais da área no país. Contudo, fica a reflexão: o que está sendo produzido? E o que significam esses dados para a pesquisa sobre publicidade e consumos digitais? Esperamos encontrar algumas respostas com a análise mais profunda desta pesquisa.

Sobre os autores, identificam-se, pelos registros, cerca de 164 com artigos individuais, em duplas ou em textos com até cinco autores. Dos 101 trabalhos sobre publicidade e consumos digitais, 52 são feitos em coautoria. As origens desses trabalhos são as seguintes:

Tabela 2. Distribuição de artigos por estados, países e instituições

\begin{tabular}{|c|c|}
\hline Estado ou país dos artigos & Instituições \\
\hline $\mathrm{RS}-31$ & UFRGS, Unisinos, PUCRS, UFSM e UCPel \\
\hline RJ -16 & UFRJ, Uerj, UFF \\
\hline$S P-16$ & ESPM, PUCSP, USP e Unesp \\
\hline$P E-7$ & UFPE \\
\hline $\mathrm{BA}-6$ & UFBA \\
\hline$M G-5$ & UFMG e UFJF \\
\hline$P R-2$ & UFPR e UTP \\
\hline $\mathrm{PB}-1$ & UFPB \\
\hline MA - 1 & UFMA \\
\hline $\mathrm{RN}-1$ & UFRN \\
\hline $\mathrm{SC}-1$ & UFSC \\
\hline \multicolumn{2}{|l|}{ Exterior } \\
\hline Portugal - 1 & Univ. Nova de Lisboa \\
\hline Espanha - 8 & $\begin{array}{c}\text { Univ. Complutense, Univ. Málaga; Univ. Vigo, } \\
\text { Univ. Rey Juan Carlos, UAb }\end{array}$ \\
\hline México - 3 & Unam \\
\hline Argentina - 1 & Univ. de Rosario \\
\hline França - 1 & Univ. Paris Descartes \\
\hline Colômbia - 1 & Univ. Manizales \\
\hline Uruguai - 1 & Univ. Nacional do Uruguay \\
\hline
\end{tabular}

Fonte: Elaborado pelo autor, 2018.

Os autores de região Sul, sobretudo do estado do Rio Grande Sul, mostram mais domínio na perspectiva de estudo dos usos e consumos midiáticos digitais do que no tema da publicidade digital, com 31 trabalhos, acompanhados por autores de região Sudeste, concentrados no eixo Rio-São Paulo (16 trabalhos do Rio de Janeiro e 16 artigos de São Paulo).

Essa distribuição de trabalhos pelos estados e instituições no Brasil é indicadora da presença de grupos/centros de pesquisas formadores que tratam dos temas da publicidade e consumos digitais, cujo resultado é muito semelhante ao identificado por Peres-Neto (2016) em seu estudo sobre a produção de teses em comunicação e consumo, já comentado. Destaca-se, ainda, a presença de dois artigos no período realizados por García Canclini, 
autor referência para os estudos de usos e consumos midiáticos e para as relações comunicação e consumo, ambos publicados na revista $C M C$.

Os demais autores apresentaram apenas um artigo no período e computam publicações nas características dos autores listados a seguir. Ademais, é importante dizer que sobre os 101 artigos, 16 eram publicações de autores estrangeiros: sete trabalhos são da Espanha (Balandron Pasos e Muela Molina, 2010, E-Compós; Calvo-Porra, Martínez-Férnandez e JuanateyBoga, 2014, RBCC; Caballo, 2016, RBCC; Kreutz e Mas Fernandez, 2009, CMC; Craveiro e Martí Pellón, 2015, CMC; Fernandez Muñoz e Garcia-Guardia, 2016, CMC; Murciano, 2010, CMC), um da Argentina (Igarza, 2010, CMC), um da Colômbia (Muñoz Gonzalez, 2008, CMC) três do México (García Canclini, 2009 e 2017 e Islas, 2012, CMC); um de Portugal (Ponte, 2012, CMC), um do Uruguai (Sanches Vilela, 2016, Famecos), um da França (Ciccheli e Octubre, 2017, $C M C$ ) e um da Inglaterra (Livingstone, 2012, CMC). Os demais textos são de autores brasileiros, pesquisadores doutores ou doutorandos e mestrandos.

Entre os autores com duas ou mais publicações, identificam-se os seguintes nomes no período de 2006 a 2017: Sandra Portella Montardo da Federação de Estabelecimentos de Ensino Superior em Novo Hamburgo (Feevale) (RS), com 6 artigos, tratando o conceito de consumo digital (MONTARDO, 2016) e os usos e consumos em plataformas digitais de comunicação. Trata-se de uma pesquisadora dotada de um PPG da Feevale multidisciplinar. Cabe destacar que esta é a autora com o maior número de publicações nos periódicos mais qualificados da área nacionalmente, que pertence a um PPG fora da área de Comunicação, mas que trabalha numa linha que contempla objetos comunicacionais; André Lemos da Universidade Federal da Bahia (UFBA), com 5 artigos, que trabalha os dispositivos móveis, seus usos e consumos midiáticos e as leituras em dispositivos digitais móveis, permitindo novas conceituações da comunicação pelo digital. É o único autor a trabalhar o aspecto de certa escritura midiática digital ao considerar as questões de leitura (LEMOS, 2012); Ana Silva L. D. Médola da Universidade Estadual Paulista (Unesp), com 4 artigos, que aborda os usos e consumos de produtos audiovisuais e da televisão digital e os regimes de interação numa perspectiva semiótica; Alex Primo da Universidade Federal do Rio Grande do Sul (UFRGS), com 3 artigos, que trata das interações nos usos e consumos de blogs e demais plataforma digitais.

$\mathrm{Na}$ perspectiva da publicidade expandida como comunicação institucional, estratégica, temos com ao menos dois artigos Eugênia Mariano Barrichello, da Universidade Federal de Santa Maria (UFSM) (RS), que trata da comunicação organizacional/estratégica e suas formas de midiatização; Marta Pinheiro da Universidade Federal de Juiz de Fora (UFJF) (MG), que aborda a espetacularização da publicidade e do trabalho com marcas nos ambientes digitais com visão sociocrítica; Rogério Covaleski, da Universidade Federal de Pernambuco (UFPE), que trabalha a comunicação de estratégia de marcas em processos de convergência midiática e ambientes digitais. Vander Casaqui, da ESPM-SP, que trabalha a representação do trabalho criativo em empresas de informação digitais (Google). Desses pesquisadores citados, apenas Rogério Covaleski, Vander Casaqui e Marta Pinheiro trabalham/trabalharam com temas da publicidade, comunicação e consumo.

Na comunicação digital, abordando usos e consumos midiáticos e as teorizações com orientações filosóficas e métodos ao campo da comunicação digital, temos com dois registros de artigos os nomes de Erick Felinto da Universidade do Estado do Rio de Janeiro (Uerj), Lúcia 
Santaella, da PUC-SP e Raquel Recuero, da Universidade Católica de Pelotas (UCPel). Esses autores, juntamente com Alex Primo e André Lemos, compõem o conjunto de autores brasileiros mais citados no âmbito dos estudos da comunicação digital no Brasil. Podemos afirmar que esses importantes autores abordam para além das questões teóricas e filosóficas da comunicação digital, os usos e consumos digitais, mas necessariamente não estudam a publicidade digital, exceto no caso de Lúcia Santaella, que publicou recentemente (2018) livro sobre redação publicitária digital.

E no que se refere aos usos e consumos midiáticos digitais, temos os seguintes pesquisadores com ao menos dois artigos publicados no período: Denise Cogo (ESPM); Rose Santini (UFRJ); Suely Fragoso (Unisinos); Mônica Pieniz (UFRGS); Lirian Sifuentes (PUCRS); Ana Carolina Escosteguy (PUCRS); Néstor García Canclini e Beatriz Polivanov (UFFRJ).

No aspecto teórico, percebe-se a utilização do conceito de cibercultura nos trabalhos com uma grande influência de Pierre Lévy. A partir de 2014 o termo vai deixando de ser utilizado, considerando-se as discussões que apontam para a contiguidade dos mundos on-line e off line e que não justificam essa diferença entre ciberespaço e espaço "real". Ambos compõem a realidade e o que importa é a compreensão dos fluxos entre esses modos/espaços de realidades.

Existe certa dominância nos artigos manifestados no tipo de escrita ensaística, pela presença expressiva de textos teóricos encontrados, pautados em exemplos empíricos, que não chegam a ser estudos de casos, como indicaria o rigor de tal método, mas que se configuram por uma revisão de literatura orientada aos interesses das discussões propostas. Isso é indicador de um possível habitus dos pesquisadores da área cujo ethos é inspirado nas reflexões ensaísticas de ciências humanas, mas que ao mesmo tempo pode se configurar como um complicador para o trabalho empírico mais sistemático na área, pelas ausências de discussões sobre métodos e caminhos de tratamentos das pesquisas com produtos e processos midiáticos e de comunicação ligados à publicidade e aos consumos. Trata-se de um dado que pode ser observado em pesquisa futura sobre o habitus dos pesquisadores desse subcampo, a publicidade e os consumos e suas práticas de investigação.

Apenas 11 artigos são resultantes de pesquisas com abordagens quantitativas (oito) ou mistas (três). Todos são de autores estrangeiros. Os poucos trabalhos quantitativos no Brasil são descritivos exploratórios com base em dados secundários. Entre os artigos estrangeiros espanhóis encontramos trabalhos estatísticos um pouco mais elaborados pelo uso de cálculos em equações estruturais para mensuração da confiança de marca, meta-análise para estudar modelagens estatísticas de usos e consumos midiáticos. No geral, mesmo os estudos quantitativos brasileiros, três ou quatro artigos, são descritivos de cenários de usos e consumos.

A maioria dos textos é abordagem qualitativa, exploratória, usando sobretudo o método da análise de conteúdo. Alguns estudos usam softwares para coleta de dados, mas são poucos os trabalhos e autores que o fazem, como Sandra Montardo, André Lemos, Alex Primo. A semiótica e a análise de discurso aparecem pontualmente para compreender as interações e os processos de enunciação com a televisão e produtos audiovisuais, a exemplo dos trabalhos de Ana Sílvia Médola, e poucos usam a análise de discurso francesa ou a crítica social ao consumo pela retórica, como o trabalho de Maria Eduarda Mota.

O digital, para a maior parte dos artigos, é mais compreendido como um espaço de mise en scéne da comunicação do que algo que interfere 
ontologicamente na construção dos processos sociais, deixando lacunas sobre as reflexões dos desafios específicos teóricos e metodológicos para os estudos de publicidade e de consumos digitais. Tal aspecto é algo que os pesquisadores do campo devem levar em consideração, pois o digital, sobretudo na questão numérica/algorítmica, precisa ser aprofundado na sua forma de escrita comunicacional e na perspectiva crítica sociopolítica para a vida social. Sabe-se que o livro de Izabela Domingues (2016) é o único, atualmente, a abordar uma perspectiva sociocrítica da vigilância algorítmica no consumo.

A perspectiva dos usos e consumos midiáticos digitais e das ações publicitárias digitais em seus usos e apropriações indicam trabalhos que abordam a cultura material e suas lógicas. Esses trabalhos passam pelos estudos dos usos de redes sociais digitais, estudos de campanhas em redes que usam a análise de conteúdo, a etnografia digital ou a netnografia.

o corpus desses trabalhos é formado por campanhas/ações online de marcas, séries, programas de tevê aberta, programas do YouTube; consumo audiovisual em várias telas, suas circulações midiáticas nas plataformas digitais (Facebook, Twitter, blogs); consumo da música nos espaços digitais; usos gerais e específicos de plataformas digitais (Facebook, Twitter, fotoblogs, Myspace, Orkut); mercados colaborativos e ações de economia criativa para consumos culturais e novas lógicas de produção/consumo.

Os trabalhos de forma global não tratam metodologicamente de big data. Certamente, isso se dá por uma deficiência de formação no campo comunicacional dos pesquisadores. Aspecto este que precisa ser superado, ou corremos o risco de não avançar nas pesquisas no âmbito digital sobre a publicidade e os consumos.

As pesquisas parecem sinalizar o trabalho com a comunicação digital, no campo dos estudos de Mídia como disciplina da Comunicação, mas estão dominantemente nas descrições de ações publicitárias e suas lógicas midiatizadoras, às vezes trazendo alguma crítica social. E no geral, o grosso dos trabalhos do eixo temático se refere aos usos e consumos midiáticos digitais, como já foi dito.

\section{CONSIDERAÇÕES FINAIS}

Diante dos limites de tempo e de páginas, reconhecemos que este artigo precisa ser bastante melhorado para uma futura publicação, incorporando mais detalhes em dados sobre teorias, assuntos e metodologias. Ademais, torna-se relevante considerar que as duas hipóteses referentes a este estudo são parcialmente verdadeiras. Há certa dispersão dos assuntos e das teorias na área da publicidade e consumos, o termo publicidade é mais escasso e a publicidade digital parece mais escassa ainda. Parte disso é fruto da expansão do conceito de publicidade que se mistura aos novos fenômenos do digital. Mas o fato é que os pesquisadores da área não estão publicando com tanta intensidade sobre o eixo temático especifico da publicidade digital nas principais revista do país. Há um consistente conjunto de reflexões ensaísticas e de pesquisas exploratórias qualitativas de consumos midiáticos digitais de qualidade no país, mas que não geram desdobramentos sobre estudos de publicidade e consumos com big data, no digital, por exemplo.

Os consumos midiáticos digitais seguem protocolos já bem difundidos, mas o aspecto digital algorítmico das formas de produção/consumo não 
é devidamente abordado em seu caráter ontológico e metodológico. $\mathrm{O}$ mise en scéne da comunicação digital domina, mas não se mergulha de fato na natureza do digital, salvo poucas exceções, aqui registradas nas menções aos autores de destaque no subcampo estudado. Falta abordar por um viés político, sociocrítico e mesmo da ontologia dos números as possibilidades da nova publicidade e dos consumos na mediação da cultura digital na vida social.

\section{REFERÊNCIAS}

BOURDIEU, P. Algumas propriedades dos campos. In: Questões de sociologia. Rio de Janeiro: Marco Zero, 1983. p. 89-94.

DOMINGUES, I. Publicidade de controle: consumo, cibernética, vigilância e poder. Porto Alegre: Ed. Sulina, 2016.

KIM, K.; HAYES, J. L.; AVANT, J. A.; REID, L. N. Trends in Advertising Research: a longitudinal analysis of leading advertising, marketing, and communication journals, 1980 to 2010. Journal Of Advertising, Abingdon, v. 43, n. 3, p. 296-316, 2014.

LEMOS, A. Dispositivos de leitura eletrônicos. Comunicação, Mídia e Consumo, São Paulo, v. 9, n. 24, p. 115-131, 2012. Disponivel em: https://bit.ly/2R81315. Acesso em: 6 jul. 2018.

MONTARDO, S. P. Consumo digital e teoria de prática: uma abordagem possível. Revista Famecos, v. 23, n. 2, p. id22203, 2016. Disponível em: https://bit.ly/2Wvhh5e. Acesso em: 11 jun. 2019.

PERES-NETO, L. Teorias da comunicação e o consumo: algumas conjecturas teóricas e prospecções. In: XXV ENCONTRO ANUAL DA COMPÓS, 2016, Goiânia. Anais [...]. Belo Horizonte: Compós, 2016. Disponível em: https://bit.ly/2X1Ua6Y. Acesso em: 6 jul. 2018.

TOALDO, M. M.; JACKS, N. Consumo midiático: uma especificidade do consumo cultural, uma antessala para os estudos de recepção. In: RIBEIRO, R. (org.). Jovens, consumo e convergência midiática. Curitiba: Ed. UFPR, 2017. p. 19-29, v. 1.

TRINDADE, E. Tendências para pensar a formação em publicidade na contemporaneidade. Revista Latinoamericana de Ciencias de la Comunicación, São Paulo, v. 14, n. 27, p. 33-41, 2017. Disponível em: https://bit.ly/2lbZEnv. Acesso em: 6 jul. 2018.

YALE, L.; GILLY, M. C. Trends in Advertising Research: a look at the content of marketing-oriented journals from 1976 to 1985. Journal of Advertising, Abingdon, v. 17, n. 1, p. 12-22, 1988. 